\title{
Espiritualidad islámica y cristiana en España: influjos, semejanzas y paralelos
}

\author{
Francisco de Borja Medina Rojas ${ }^{1}$
}

Fecha de recepción: octubre 2020.

Fecha de aceptación: octubre 2020.

\section{Sumario:}

Dos culturas, la islámica y la cristiana, que en principio parecen antagónicas, debido al estrecho contacto que han mantenido en algunos momentos de la historia, nos presentan influencias mutuas. A lo largo de este breve ensayo intentaremos mostrar al lector unas breves muestras de ese intercambio entre ambas culturas, para que estas puedan servir de base a diálogos actuales, por lo que acabamos estableciendo cual es el estado de la cuestión, sobre esos paralelismos y semejanzas entre las mencionadas espiritualidades.

\section{Palabras clave:}

Diálogo, cultura, espiritualidad, cristianos, musulmanes.

\author{
Islamic and christian spiritualities in \\ Spain: influences, similarities, and \\ parallels
}

\begin{abstract}
:
Two cultures, the Islamic and the Christian, that, at first sight seem antagonistic, yet due to the close contact maintained by both of them in some moments of history, offer us mutual influences. All along this essay we shall endeavor to show to the reader some brief samples of that interchange between the two cultures, so that they may serve as a foundation for present day dialogues, and by this we finish establishing which is the state of the question, about these parallelisms and similarities between the mentioned spiritualities.
\end{abstract}

\section{Keywords:}

Dialogue, culture, spirituality, Christians, Moslems.

\footnotetext{
${ }^{1}$ Investigador independiente. https://orcid.org/0000-0001-7722-8669<medina@sjcuria. org>

NOTA: Ensayo presentado como lección en el Seminario interreligioso internacional celebrado en la Universidad Gregoriana en unión con la universidad de Ankara (Turquía). Publicado en la versión inglesa mejorada y completada con notas: «Islam and Christian Spirituality in Spain: Contacts, Influences, Similarities» Islamochristiana (Pontificio Istituto di Studi Arabi e d'Islamistica) 18 (Roma 1992) 87-108.

El texto inglés de mi lección, traducido del original español y corregido por mí, se publicó más tarde: Islam and Christian Spirituality in Spain: Contacts, Influences, Similarities en Yunus Emre: Spiritual Experience and Culture. International seminar. Rome, November 6-9, 1991. Gregorian University and University of Ankara. Inculturation. Working Papers on Living Faith and Cultures (Roma: Editrice Università Gregoriana, 1994), 43-56.
} 
El tema que se me ha asignado aparece tan amplio que es imposible abarcarlo en una comunicación que necesariamente debe ser breve. Me propongo sólo exponer el estado de la cuestión del posible parentesco de los aspectos espirituales presentes en dos culturas aparentemente antagónicas: islam y cristianismo. Este parentesco, aceptado mayoritariamente por los estudiosos en puntos fundamentales, es sumamente debatido en cuanto a la amplitud del fenómeno y a su particularización.

Propondré primero brevemente algunos rasgos fundamentales del contexto histórico en que se desarrolló la intercomunicación cultural de la España cristiana y musulmana para enumerar, luego, los posibles influjos mutuos, entre ellos el de la espiritualidad. Finalmente, expondré el estado de la cuestión fijándome, sobre todo, en dos casos que ofrecen mayor interés a los estudiosos: los místicos españoles reformadores de la Orden del Carmen, santa Teresa y san Juan de la Cruz.

Los nueve siglos de convivencia, o si queremos, coexistencia, en España de las tres culturas -cristiana, judía y musulmana- no pudo menos de marcar la vida española a todos sus niveles. También el de las vivencias espirituales en su más amplio espectro. He dicho nueve siglos, porque cuento hasta 16091614 en que se consuma la expulsión de los moriscos cuya inmensa mayoría (no era ningún secreto) o era criptoislámica, o abiertamente islamizante.

Símbolo de esta convivencia, en el siglo XIII, podría ser el epitafio de Fernando III de Castilla (San Fernando), conquistador de los tres reinos musulmanes bañados por el Guadalquivir (Córdoba, Jaén, Sevilla) ayudado por el rey nazarí de Granada.

Fernando muere en Sevilla en 1252. Su tumba se encuentra en la Capilla Real de la catedral: en los laterales, se encuentran cuatro lápidas sepulcrales, dos a cada lado, con sus respectivas inscripciones: latín y castellano, en el lateral derecho, árabe y hebreo en el izquierdo. Su autor, Alfonso X, apodado el Sabio, hijo y sucesor de Fernando.

El texto de las cuatro inscripciones es fundamentalmente el mismo, pero cada lengua utiliza el propio cómputo para la fecha de la muerte: año de la Encarnación (último día de mayo 1252), Era hispana (postrimero día de mayo 1290), Hégira (noche del viernes, día 21 del mes de Rabí primero, del año 650), año de la Creación del mundo (noche del viernes, 22 del mes de Siwan, del año cinco mil doce).

En las tres versiones vernáculas se suprimen las frases de la versión latina referentes a la conquista de Sevilla cuyo sentido de re-conquista cristiana, pueden herir la susceptibilidad de las otras religiones: «de manibus eripuit paganorum et cultui restituit christiano». Así como la fórmula cristiana de expresar la muerte: «ubi solvens naturae debitum ad Dominum trasmigravit». 
En las versiones árabe y hebrea se introducen las exclamaciones propias de cada cultura religiosa: «Alá se apiade de él», «sea su alma en el Jardín del Edén». Ninguna fórmula especial se usa en la castellana.

La letanía de las virtudes del rey difunto desgranadas en su eulogio podía ser aceptada por todos. He aquí la versión literal castellana:

AQVI : IAZE : EL : REY : MUY : ONDRADO : DON : FERNANDO : SEÑOR : DE : CASTIELLA : E : DE : TOLEDO :DE : LEON :DE : GALIZIA : DE : SEVILLA : DE : CORDOVA : DE : MURCIA : DE : IAHEN : EL : QUE : CONQUISÓ : TODA : ESPAÑA : EL : MÁS : LEAL : EL : MÁS : VERDADERO : EL : MÁS : FRANCO : EL : MÁS : ESFORÇADO : E : EL : MÁS : APUESTO : E : EL : MÁS : GRANA$D O: E$ : EL MAS : SOFRIDO : E : EL MAS : OMILDOSSO : QUE : MÁS : TEMÍE : A DIOS : EL : QUE : MÁS : LE : FACÍE : SERVICIO : EL : QUE : QUEBRANTÓ : E : DESTRUYÓ : A : TODOS : SUS : ENEMIGOS : EL : QUE : ALZÓ : E : ONDRÓ : A : TODOS : SUS : AMIGOS.

Uno de estos amigos había sido el señor moro de Arjona (en el reino de Jaén), Muammad Ibn Yūsuf Ibn al-Amar, que en 1240 se había autoproclamado, en Granada, Amir al-Muslimīn, al que ayudó Fernando a obtener y conservar el trono y ofreció su protección, a cambio del vasallaje.

Cada lengua utiliza los equivalentes vernáculos del territorio donde viven bajo el mismo soberano, patria común a todos: Hispania, España, Sefarad, Al-Andalus. De aquí que a los judíos españoles se llamen sefardíes y a, los musulmanes, andalusíes. Este es el nombre que usaremos para los musulmanes españoles.

Coexistieron tanto comunidades cristianas en los territorios bajo el Islam, los llamados mozárabes, como comunidades islámicas en los reinos cristianos, los mudéjares. Del mismo modo, se dieron conversiones en ambos sentidos. Hubo maulas, o muladies en los territorios bajo el dominio musulmán, y tornadizos en los reinos cristianos. En ambos territorios habitaban comunidades judías y conversos pasados de esta religión a una de las otras.

Esta tolerancia, no obstante sus tensiones y dificultades, se reconoce oficialmente en el siglo XIII por Alfonso X en su Ley de las Siete Partidas, ordenamiento jurídico de Castilla, base de la legislación castellana y, luego, española, durante siglos.

En la legislación alfonsí no se renuncia a la atracción de otros a la propia fe, que es punto común a ambas religiones, pero se hace desde una perspectiva de respeto a la libertad personal. En la ley II, título XXV de la Partida VII, se manda: 
Por buenas palabras, e convenibles predicaciones deben trabajar los Christianos de convertir a los Moros para facerles creer la nuestra fe, e aducirles a ella e non con fuerça, ni por premia: ca si voluntad de nuestro Señor fuese de los aducir a ella, e gela fazer creer por fuerça, el los apremiaría, si quisiese, que ha acabado poderío de lo fazer, mas él non se paga del seruicio qual hazen los omes a miedo, mas de aquel que se faze de grado, e son premia ninguna: e pues él no los quiere apremiar, ni fazer fuerça, por esto defendemos, que ninguno los apremie, ni les faga fuerça sobre esta raçón.

En esta política del rey castellano, inspirada en el modo de actuar de Dios, se ha querido ver un influjo de la tolerancia coránica respecto de la gente del Libro [al-kitab].

Pero es significativo que, en el siglo anterior, los invasores africanos, almorávides y almohades, habían implantado la intolerancia en los reinos andalusíes. Cristianos y judíos se habían visto obligados a emigrar a los reinos cristianos. El mismo camino se recorrerá en éstos durante los siglos XIV y XV hasta llegar a la disyuntiva trágica (o conversión al cristianismo o expulsión) exigida por el poder real, primero a los judíos en 1492 y, poco después, a los musulmanes, en tres etapas: 1499-1501 a los granadinos, 1502 a los mudéjares de la corona de Castilla y 1525 a los de la corona aragonesa.

Este cambio radical de actitud se refleja en el epitafio del sepulcro de los Reyes Católicos, Fernando e Isabel, en la Capilla Real de Granada, diametralmente opuesto al de san Fernando en Sevilla. Escrito en una sola lengua, en latín, y sin más eulogio que su actuación religiosa represiva:

\section{MAHOMETICE SECTE POSTRATORES ET HERETICE PERVICA- CIE [judios] EXTINTORES FERNANDUS ARAGONUM ET HELISA- BETHA CASTELLE VIR ET UXOR UNANIMES CATOLICE APPE- LLATI MARMOREO CLAUDUNTUR HOC TUMULO.}

En cuanto a la intercomunicación, en los largos periodos de paz o de treguas, cristianos y musulmanes se visitaban, comerciaban entre sí, se unían en matrimonio, sus reyes se prestaban ayuda en sus respectivas guerras civiles, se refugiaban los unos en los reinos de los otros en épocas de turbulencias.

La brillante civilización cordobesa inaugurada ya por Abderramán II en el siglo IX, atraía a los cristianos de los reinos peninsulares en los que influyó en el arte, vocabulario, organización militar y judicial, ciencias y filosofía, literatura y bellas artes. Disuelto y desmembrado el califato, la cultura continuó en los reinos taifas durante el siglo XII y pasó también a la corte castellana. 
Toledo, re-ocupada en 1085, por Alfonso VI, se convierte en el centro más importante de irradiación de la cultura islámica hacia el resto de la Península y Europa. Alfonso tomó el título de rey de las tres religiones y su corte asemejaba una corte musulmana: el rey rodeado de sabios y literatos musulmanes y judíos, vestido a la moda árabe, o como se decía: a la morisca. Incluso los clérigos mozárabes de Toledo usaban nombres árabes, hablaban en árabe y conocían poco el latín.

A través de la llamada enfáticamente escuela de traductores de Toledo, establecida durante el reinado de Alfonso VII por el arzobispo toledano D. Raymundo, se dan a conocer en Europa las obras más célebres de la ciencia arábiga: matemáticas, astronomía, medicina, alquimia, física, historia natural, metafísica, psicología, lógica, moral y política, así como las obras greco-latinas glosadas por filósofos árabes.

Dos siglos más tarde, con Alfonso X (1252-1284), se trasmitió a Occidente la ciencia árabe oriental y los tesoros de la cultura andalusí de los siglos XI y XII. Reunió en torno suyo a musulmanes, judíos y mozárabes, sistematizó los trabajos de traducción en Toledo y empleó la lengua castellana como vehículo de cultura. Las traducciones se hacían en equipo por alfaquíes, rabinos y clérigos. Entre otras obras se tradujeron al castellano Calila y Dimna, colección de fábulas orientales y la Escala de Mahoma (al-Miray), viaje nocturno del Profeta (azora 17, v. 1.). Del castellano se tradujo al latín y francés e influyó en la Divina Comedia de Dante Alighieri.

Alfonso creó en Sevilla un Estudio y Escuela General de latín y árabe para el estudio de las ciencias y encargó al filósofo murciano, Muammad al-Ricotí, la dirección de una escuela en Murcia destinada a la enseñanza de musulmanes, judíos y cristianos.

En el último cuarto del siglo XVIII, el ex-jesuita Juan Andrés, desterrado en Italia, había vislumbrado en su obra enciclopédica Dell origine, progressi e stato attuale d'ogni letteratura (7 tomos 1782-1799) lo que la cultura europea medieval debía a los árabes españoles. Su obra, reeditada repetidamente en Italia, se tradujo muy pronto al castellano, al francés y al alemán. En literatura, defendió el origen arábigo de la rima y del metro de los trovadores, lo que equivalía a propugnar el mismo origen para toda la poesía europea, que reconoce en la provenzal su inmediato precedente. 


\section{La formación de España}

Pero este es sólo un aspecto formal del problema. La convivencia de las tres culturas durante casi un milenio no ha podido dejar de afectar el devenir de España y la formación de su substrato. Este dato evidente ha desencadenado acaloradas polémicas a la hora de determinar y cuantificar la aportación de cada una de las culturas.

Aún está presente la polémica suscitada por la obra de Américo Castro España en su historia. Cristianos, moros y judios (Buenos Aires 1948) que tomó caracteres más universales al entrar en liza Claudio Sánchez Albornoz con España, un enigma histórico (Buenos Aires 1956).

La tesis de Castro, refundida en su La realidad histórica de España (México 1954) reeditada varias veces (70 ed.1980), otorga la primacía al influjo de lo islámico en la contextura de lo español en todos los ámbitos de la vida. Para él no comienzan a existir los españoles hasta la invasión árabe en 711. En la práctica niega todo influjo del elemento romano-visigodo y asigna a lo judío un influjo en la formación de la literatura castellana y, a partir del siglo XV, en los diversos aspectos de la vida religiosa que continuará, a través de los conversos, en el siglo XVI. Son éstos, según Castro, los que dieron el impulso a la renovación espiritual de Castilla.

Sus postulados dieron lugar a las más variadas posiciones, desde el rechazo total hasta la aceptación más completa. Esta fue más general entre los estudiosos de la literatura que entre los historiadores. Las posturas se polarizaron. Los críticos se agruparon en torno a uno u otro extremo. Intervinieron, oponiéndose o puntualizando, Ramón Menéndez Pidal, Emilio García Gómez, Leo Spitzer, Marcel Bataillon, Eugenio Asensio, entre otros. José Luis Gómez Martínez ha estudiado los avatares de la polémica en Américo Castro y el origen de los españoles: historia de una polémica (Madrid 1975).

Se ha dicho que los planteamientos de Castro han constituído el intento más complejo y sistemático de analizar el pasado hispano en una época crucial de su formación. Pero, como señalaba Marcel Bataillon, Castro hacía historia vertical, es decir, diacrónica, cortando los estratos del acontecer hispano-musulmán, pero descuidaba la horizontalidad de la relación de lo español con lo europeo, le faltaba, en una palabra, el aspecto sincrónico. Ortega y Gasset hacía ver que el elemento germánico (godo) era el fundamental integrador de lo español. Y Sánchez Albornoz insistía en la formación de lo español desde el reino cristiano Leonés, heredero del romano-visigodo. Este núcleo desplazaría lo islámico y repoblaría los territorios de Al-Andalus dejados por los musulmanes. 


\section{Misticismo islámico y cristiano}

Por otros caminos, pocos años antes de la obra polémica de Castro, Miguel Asín Palacios señalaba, a través de sus estudios de autores místicos andalusíes, la analogía de doctrina y lenguaje de los maestros sufíes del siglo XII con los místicos cristianos españoles de siglo XVI y, más en particular, con los reformadores de la Orden del Carmen, Santa Teresa y San Juan de la Cruz.

La mística andalusí había ido reelaborando con su propia sensibilidad las doctrinas y métodos del sufismo oriental dando lugar a una escuela propia. El primer maestro con originalidad, sería Ibn Masarra, del siglo X, al que Asín dedica un trabajo en 1914 Abenmasarra y su escuela. Sus concepciones, enseñadas por sus discípulos, constituyó la base doctrinal de la mística andalusí.

Uno de los que se inspiran, en parte, en esta escuela es Abenarabí de Murcia (m. 1240), a cuya vida y obra dedicó Asín una serie de cuatro artículos en el Boletín de la Real Academia de la Historia (entre 1925-1928), anticipo de su amplio estudio El Islam cristianizado. Estudio del sufismo a través de las obras de Abenarabi de Murcia (Madrid 1931). El mismo título indica la orientación de su tesis. A diferencia de Louis Masignon que defiende el origen autónomo del sufismo en Essai sur les origines du lexique technique de la mystique musulmane (Paris 1922), Asín basa las semejanzas en la «restitución cultural». Usando sus propias palabras,

el Islam se nos ofrece [...] bajo un doble aspecto: como trasmisor del Oriente a Europa del legado cultural clásico y cristiano y como acrecentador de este caudal por su personal esfuerzo e inventiva, porque los préstamos que la mano oriental tomó del tesoro helénico y patrístico devolviólos luego y con creces a sus acreedores cristianos de Occidente.

Por una parte, en 1916, como fruto de su investigación sobre los posibles influjos cristianos en la mística islámica, Asín había publicado, en Patrologia Orientalis (XIII, 3. Paris 1916), Logia et Agrapha D. Jesu, donde recogía 233 textos de espirituales musulmanes sobre frases y hechos atribuidos a Jesús. Y, por otra parte, en 1919, en La Escatología musulmana en la Divina Comedia, había puesto de relieve los préstamos del Islam, en la obra cumbre del Dante, así como las fuentes bíblicas y evangélicas de las doctrinas islámicas sobre la vida de ultratumba.

De modo semejante, la espiritualidad sufí tendría, en parte, su origen remoto en el monacato cristiano de Oriente y en los anacoretas del desierto. Asín lo explica en su extensa obra, en tres tomos, La espiritualidad de Algazel y su sentido cristiano (1934-1940). Se manifiestan en el Islam dos corrientes: 
la ortodoxa, representada por Algazel, y la heterodoxa, de la que forma parte Abenarabí de Murcia. Las analogías con los místicos españoles vendrían dadas por este origen cristiano.

En El Islam cristianizado, Asín examina, entre otros aspectos, la doctrina espiritual y el método de Abenarabi de Murcia y señala sus coincidencias con los espirituales españoles del siglo XVI. Así, entre los medios para alcanzar la perfección, cita, por ejemplo, el examen de conciencia y la presencia de Dios. El examen, de origen monacal cristiano, lo perfeccionan, en el Islam, Algazel y Abenarabi y Asín encuentra semejanzas con el método de San Ignacio de Loyola en sus Ejercicios Espirituales. En cuanto a la presencia de Dios, las coincidencias se darían en Santa Teresa y San Juan de la Cruz.

Asín estudiaba también, en «Un precursor hispano-musulmán de San Juan de la Cruz», el influjo de la mística islámica en el reformador del Carmelo a través de otro místico andalusí, Ibn Abad de Ronda (m. 1389). Publicado en Al-Andalus en 1933 y editado, luego, en Huellas del Islam (1941), recopilación de estudios sobre el influjo islámico en autores cristianos, Asín pasa revista a la doctrina de Ibn Abad de Ronda expuesta en su Comentario a las «Sentencias de Ibn Atta Allah de Alejandría», sobre la renuncia a los carismas, el amor a las tribulaciones, el símil de la noche etc., y analiza sus analogías con la temática de la Noche Oscura en san Juan de Cruz. Le parece que son tan evidentes las semejanzas que no pueden explicar por simple coincidencia o paralelismo funcional nacido de una misma experiencia psicológico-espiritual.

Rastreando los posibles cauces de trasmisión, Asín propone una hipótesis sugestiva: el influjo de los maestros de la espiritualidad musulmana en los místicos heterodoxos y ortodoxos españoles del siglo XVI, a través de los moriscos, esto es, de los mudéjares españoles bautizados bajo la amenaza de expulsión que, en su gran mayoría, conservaron la fe y las prácticas islámicas. Estos estarían, al menos, en contacto con los shadilíes de Túnez donde se conservaba la tradición espiritual andalusí. Tema que prosigue en una serie de artículos póstumos en Al-Andalus, de 1944 a 1951, recopilados y editados recientemente, con una introducción, por la hispanista portorriqueña Luce López-Baralt: Sadilies y alumbrados (Madrid 1990).

Asín toca también el problema de los místicos «heterodoxos» que aparecieron en el siglo XVI español, los llamados «alumbrados». Ve sus raíces en los grandes maestros shadilíes. Trata, entre otros aspectos, de la oración mental y vocal, del recogimiento y quietud, de la contemplación en Miguel de Molinos, del símil del castillo o moradas de Santa Teresa... Su trabajo, inacabado por su muerte, constituye una de las aportaciones más significativas al estudio de la mística comparada en lo que va de siglo. 


\section{La «restitución cultural» de Miguel de Asín}

En cuanto a la hipótesis de la «restitución cultural», apellidada teoría arabista, se ha ido abriendo cauce en medio de dificultades y opositores, entre éstos Louis Massignon. Helmut Hatzfeld, en Estudios literarios sobre mística española (Madrid 1955), reseña el estupor y la oposición que causó a sus comienzos las tesis de Asín y hace ver cómo, aunque no todos los elementos tengan un origen árabe, hay que tener éstos en cuenta, a la hora de fijar modelos y fuentes.

El mismo año de la aparición del Islam cristianizado de Asín, Angel González Palencia, en su discurso de recepción en la Real Academia de la Historia (31 mayo 1931), partiendo de los atisbos de Juan de Andrés sobre el influjo de lo islámico en Occidente, hacía un recorrido por todos los campos del saber en que Europa y España eran deudores del Islam. Se hace ya eco de las tesis de Asín sobre el influjo islámico en la mística española cristiana. Este discurso y su posterior conferencia en la Universidad de Granada en 1937, Huellas Islámicas en el carácter español, donde elenca, en un apéndice, las ediciones europeas de los siglos XV y XVI de la versión latina de las obras de 60 autores árabes, marca un hito en la comprensión de los influjos islámicos en el devenir cultural de España. Ambos trabajos, junto con otros relacionados con el tema, se editaron en Moros y Cristianos en España Medieval, en 1945, tres años antes que Américo Castro levantara la polémica con su obra España en su Historia.

Claudio Sánchez Albornoz, a quien agradó y atrajo la tesis de Asín, la resume y la hace propia en La España musulmana (1946, 70 ed. 1986), pero insistiendo y simplificando quizás en exceso el influjo cristiano en el Islam. Lo cual apoyaba sus puntos de vista en la polémica con Castro.

El Islam -dice Sánchez Albornoz-sufrió pronto una honda influencia del cristianismo. Profundamente cristiana fue la actitud de muchos sufies de la escuela shadilí. Hay que buscar el origen de su postura mística en la doctrina paulina de los padres del yermo y del monacato oriental.

En el siglo XV un místico andaluz, Ibn Abbad de Ronda (m. 1394) escribe unos «Comentarios a las sentencias de Ibn Atta Allah de Alejandría». En la mística del Rondí aparece una tabla de preferencias y un léxico análogos a los que había de mostrar San Juan de la Cruz, y la misma renuncia a los carismas o favores divinos y el mismo amor a las tribulaciones de los místicos carmelitanos. Como concluye, Sánchez Albornoz, esas extrañas coincidencias han permitido a Asín establecer el enlace entre los dos grupos 
contemplativos hispanos: entre el musulmán de los siglos XIV y XV y el cristiano del XVI.

Hasta aquí, Sánchez Albornoz. Esta hipótesis, como indicábamos arriba, expuesta de modo unilateral por su excesiva simplificación, contradice la sostenida por Louis Masignon sobre el origen autónomo del sufismo. En su estudio sobre su fundador, La passion de Hallaj (Paris 1922, 1975), afirma Massignon que es en el Corán donde se basa el misticismo musulmán, sin necesidad de acudir a otras fuentes foráneas. Admite la absorción por el Islam de gentes procedentes del cristianismo, judaísmo o mazdeísmo, pero niega que haya que recurrir a ninguna de estas influencias para explicar la doctrina y experiencia sufíes. Paul Nwyia confirma esta posición en sus análisis de otros escritos del sufismo.

Recientemente, la ya citada Luce López Baralt, ha dedicado numerosos trabajos al estudio de las influencias islámicas en la expresión poética y en la simbología de la mística del reformador de Carmelo en San Juan de la Cruz y el Islam (México 1985, Madrid 1990). Coetáneo de esta obra es su ensayo de más amplio espectro Huellas del Islam en la literatura española (Madrid 1985,1989). Sus estudios versan sobre el vino o la embriaguez mística, la noche oscura, la llama de amor viva, el agua y la fuente, la subida al monte, el pájaro solitario, etc., a los que añade el castillo interior, o moradas de Santa Teresa.

En la filiación del soneto anónimo «No me mueve mi Dios para quererte» se inclina a ver una dependencia de Rabià al-Àdawiyya de Basora (m. h. 801), introductora del tema del amor puro entre los sufíes.

La autora estudia los posibles cauces de trasmisión o fuentes intermedias de inspiración de san Juan de la Cruz y santa Teresa. Uno podría ser la literatura mística europea, influenciada a su vez, en el medioevo, por autores islámicos como Algazel y Avicena. Pero, las semejanzas, en los casos estudiados, serían más cercanas a la fuente originaria islámica que a las intermedias. Por otro lado, admite el influjo de la exégesis judía. De todos modos reconoce que, no obstante las evidentes semejanzas, aún no se ha encontrado el eslabón perdido.

Paul Nwyia se muestra sumamente cauto a la hora de aceptar el influjo sufí o shadilí en San Juan de la Cruz, en particular de Ibn Abad de Ronda. En su artículo «Ibn Abbad de Ronda et Jean de la Croix», aparecido en Al-Andalus en 1957, pasa revista a las afirmaciones de Asín al propósito, en particular en relación con la terminología de anchura (bas) y apretura ( $q a b d)$ o, en leguaje ignaciano, los opuestos consolación-desolación así como la doctrina sanjuanista subyacente: el símbolo de la noche y la renuncia a los carismas. Nwyia piensa que los textos aducidos del Rondí son muy sugestivos, pero, al 
extraerlos de su contexto semántico, pierden su valor de modelo e indicarían semejanzas más que filiaciones.

La misma reserva, había mostrado Massignon en Etudes Carmélitains (octubre 1938) «Textes musulmans pouvant concerner la nuit de l'esprit». En cuanto al cauce de trasmisión, Nwyia, al igual que Jean Baruzi, a quien cita, sin rechazar la hipótesis de Asín, sobre el medio morisco, propone, antes de llegar a conclusiones, un estudio serio del medio y contactos de San Juan de la Cruz con el mismo.

Estudios recientes han abordado el origen neo-cristiano de San Juan de la Cruz, suponiéndolo hijo de judío y morisca, cercano, por tanto, a este medio. Pero ni se ha probado este doble origen ${ }^{2}$, ni se ha confirmado la hipótesis del conocimiento de las doctrinas shadílies afines a Ibn Abad y a sus discípulos en los medios moriscos.

Como hace ver López-Baralt, los numerosos trabajos recientes sobre la literatura aljamiada morisca, no corroboran, por ahora, la hipótesis de Asín. Los moriscos coetáneos de los autores espirituales españoles parecen desconocer la literatura mística islámica de sus antepasados andalusíes.

Por otra parte, no se puede negar el influjo directo de la espiritualidad islámica en otros autores cristianos. Juan Vernet, por ejemplo, en su obra reciente Ce que la culture doit aux Arabes d'Espagne (1985) trata, entre otros temas, del influjo del Islam en el franciscano Ramón Llull (1231-1315). Es la tesis defendida ya por Julián Ribera en 1899, «Orígenes de la filosofía de Raimundo Lulio» $»^{3}$ y por Asín, en la misma ocasión, en su trabajo «Mohidin» ${ }^{4} \mathrm{y}$, años después, en el ya citado Abenmasarra y su escuela. Asín minusvalora este influjo en «El lulismo exagerado» ${ }^{5}$. Pero otros no dudan de la importancia del influjo sufí en Llull y de éste en la mística cristiana bajo-medieval y posterior.

Llull aprende árabe, promueve, en Europa, la fundación de cátedras y escuelas de orientalismo y escribe varias de sus obras, en árabe. A través de la lectura personal, sus fuentes directas de inspiración son los místicos andalusíes, en particular Ibn Arabí de Murcia. De filiación islámica son: Els cent noms de Deu, Llibre de les besties, la novela autobiográfica Blanquerna. En concreto, El libre d'amic y d'amat, según confiesa, en Blanquerna, lo escribió, según el método de los sufíes. Incorpora las ideas islámicas de la oración mental, en su libro Oracions de Ramon.

\footnotetext{
${ }^{2}$ Véase, por ejemplo, José Gómez-Menor Fuentes, El linaje familiar de Sta. Teresa y de S. Juan de la Cruz (Toledo: Gráficas Cervantes, 1970).

${ }^{3}$ Homenaje a Menéndez y Pelayo II.

${ }^{4}$ Ibídem.

${ }^{5}$ Cultura española 1 (1906): 533-541.
} 
El influjo de Llull, en la escuela franciscana, fue notable, hasta el punto de crearse cátedras de lulismo. Sus conceptos pasan a los autores espirituales franciscanos del siglo XVI, como Francisco de Osuna, en su Tercer abecedario espiritual, cuyo influjo, en santa Teresa, se admite normalmente.

Para terminar, una palabra sobre los libros plúmbeos del Sacro Monte de Granada. Son la piedra de toque para comprobar la total ignorancia de la cultura islámica, en los teólogos españoles del siglo XVI-XVII, al mismo tiempo que, el lenguaje ambiguo de sus falsificadores, con toda probabilidad dos moriscos granadinos: Alonso del Castillo y Miguel de Luna.

Ignacio de las Casas, jesuita morisco granadino, como ellos, conocedor del Islam, descubrió el fraude al reconocer, en los libros, el pensamiento islamizante, basado en le Corán y en otras tradiciones que circulaban entre los moriscos, entre otras, la Escala de Mahoma, ya mencionada.

No pocos teólogos españoles (sólo los de la Compañía de Jesús fueron veinte de los mas conocidos de los siglos XVI-XVII), aceptaron los libros como documentos de origen apostólico del siglo I. Encontraron, en ellos, la prueba evidente de la venida de Santiago a España, la doctrina de la Inmaculada Concepción de María y una de las fórmulas trinitarias, según ellos, más antiguas. Esta fórmula, como lo mostró Ignacio de las Casas, era islámica: «Sólo Dios es Dios, Jesús Espíritu de Dios».

Baste con este recorrido para dar conocer el estado de la cuestión. Resumiendo, podemos decir:

1. La convivencia de las tres culturas, en España, durante casi un milenio, no ha podido menos de influenciar la contextura de los múltiples aspectos del ser y existir de lo español.

2. Uno de esos aspectos fundamentales es la espiritualidad musulmana andalusí, en particular, el sufismo y shadilismo.

3. Esta espiritualidad se expresa, con un léxico y una simbología, que presentan extraordinarias analogías con los autores espirituales cristianos del siglo XVI.

4. Esto se observa, sobre todo, en las dos grandes figuras de la reforma carmelitana: santa Teresa y san Juan de la Cruz.

5. Sin embargo, hasta ahora no se ha encontrado el cauce de trasmisión

a) No a todos satisface la teoría de la «restitución cultural», que se basa en un supuesto influjo del cristianismo en la mística islámica y de ésta en la cristiana.

b) Dadas las estrechas analogías de lenguaje y símbolos, de estos autores con los místicos andalusíes, tampoco satisface la tesis de una trasmisión indirecta a través de escuelas medievales cristianas, como la franciscana-luliana, influidas, por algunos aspectos del sufismo. 
c) Por otra parte, queda aún por verificar la hipótesis de la conservación de las doctrinas y prácticas sufíes y shadilíes, en la comunidad morisca.

6. Mientras no se encuentre el «eslabón perdido», tendremos que contentarnos con la constatación de paralelismos y semejanzas que, según otra hipótesis, pudieran estar originados de modo autónomo, no por influjo directo, sino por experiencias espirituales similares.

a) Estas experiencias, realizadas en un entorno vital, igual o parecido, se expresarían con un lenguaje imaginativo y una simbología tomada del ambiente circundante, del que forman parte los libros sagrados que contienen, en sí, evidentes paralelismos. Basta haber vivido, en las regiones, en que habitaron los místicos musulmanes, en Al-Andalus, para participar, al menos en el aspecto estético, de las mismas experiencias y expresarlas, en un leguaje imaginativo y simbólico muy parecido.

b) Finalmente, en cuanto la experiencia religiosa, profundamente mística, se basan en la fe en un Dios transcendente, común a ambas religiones, que se hace cercano, con sus dones, a los creyentes que le buscan con corazón sincero. 
